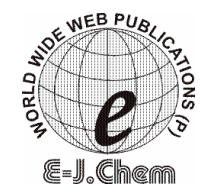

http://www.e-journals.net

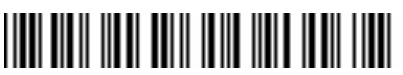

ISSN: 0973-4945; CODEN ECJHAO

E-Journal of Chemistry

Vol. 5, No. 1, pp. 58-67, January 2008

\title{
Development and Validation of LC Method for the Determination of Famciclovir in Pharmaceutical Formulation Using an Experimental Design
}

\author{
SRINIVAS VISHNUMULAKA, NARASIMHA RAO MEDICHERLA, \\ ALLAM APPA RAO and G EDELA SRINUBABU* \\ Center for Biotechnology, \\ College of Engineering, Andhra University, \\ Visakhapatnam-530003, India. \\ srinubabuau6@gmail.com
}

Received 23 April 2007; Accepted 20 June 2007

\begin{abstract}
A rapid and sensitive RP-HPLC method with UV detection (242 nm) for routine analysis of famciclovir in pharmaceutical formulations was developed. Chromatography was performed with mobile phase containing a mixture of methanol and phosphate buffer $(50: 50, v / v)$ with flow rate $1.0 \mathrm{~mL} \mathrm{~min}$. Quantitation was accomplished with internal standard method. The procedure was validated for linearity (correlation coefficient $=0.9999$ ), accuracy, robustness and intermediate precision. Experimental design was used for validation of robustness and intermediate precision. To test robustness, three factors were considered; percentage $\mathrm{v} / \mathrm{v}$ of methanol in mobile phase, flow rate and $\mathrm{pH}$; flow rate, the percentage of organic modifier and $\mathrm{pH}$ have considerable important effect on the response. For intermediate precision measure the variables considered were: analyst, equipment and number of days. The RSD value $(0.86 \%, n=24)$ indicated an acceptable precision of the analytical method. The proposed method was simple, sensitive, precise, accurate and quick and useful for routine quality control.
\end{abstract}

Keywords: Famciclovir, Column liquid chromatography, Robustness testing, Experimental Design, Intermediate precision and validation

\section{Introduction}

Chemically, famciclovir (FCV), known as 2-[2-(2-amino-9H-purin-9-yl) ethyl]-1, 3propanediol diacetate (Figure 1) is a novel antiviral drug, which is highly efficient in treatment of acute uncomplicated herpes zoster. It was reported that FCV dosed at $250 \mathrm{mg}$ 
three times daily for 7 days was effective as $800 \mathrm{mg}$ acyclovir dosed five times daily for 7 days in the treatment of the acute signs and symptoms of herpes zoster ${ }^{1}$. This drug is also used for the treatment of the ophthalmic zoster ${ }^{2}$. FCV is a synthetic guanine derivative, which is metabolized to penciclovir having the potent antiviral activity as another 9-substituted guanine derivative like acyclovir. Penciclovir is active against herpes simplex virus type 2, vericella zoster virus I, Epstein-Barr virus and hepatitis $\mathrm{B}^{3}$, as another 9-substituted guanine derivative like acyclovir, penciclovir is selectively phosphorylated in virus-infected cells to a monophosphate ester by thymidine kinase, followed by further phosphorylation to triphosphate ester which inhibits virus DNA polymerases ${ }^{4}$. Compared with acyclovir, penciclovir administration leads to higher triphosphate ester concentrations in virus-infected cells and consequently its antiviral activity persists for a longer time after removal of the compound ${ }^{4-5}$. FCV is absorbed rapidly and extensively after oral administration, and total systemic availability of penciclovir is $77 \%^{6}$, which is about four times higher than that of acyclovir ${ }^{7}$. Metabolism of FCV involves sequential hydrolysis of both acetyl groups to give 6- deoxypenciclovir, which is subsequently oxidized to penciclovir ${ }^{8}$, penciclovir determination in plasma was developed by F.Schken et $\mathrm{al}^{9}$, which was synthesized by Briony brand et al. ${ }^{10}$. FCV stability in different buffer solutions was studied by Zhang et al. ${ }^{11}$. Since FCV is widely used in the antiviral therapy, it is important to develop and validate analytical methods for its determination in pharmaceutical dosage form. The present work reports the development and validation of a HPLC method and a UV method for the estimation of FCV in tablets. So for no systematic HPLC method has been reported for determination of FCV in pharmaceutical injections. This paper reports a rapid and sensitive HPLC determination method with UV detection, useful for routine quality control of FCV in pharmaceutical formulations. The method was validated by parameters such as linearity, accuracy, precision and robustness. Experimental design was used for validation to evaluate the robustness and intermediate precision.

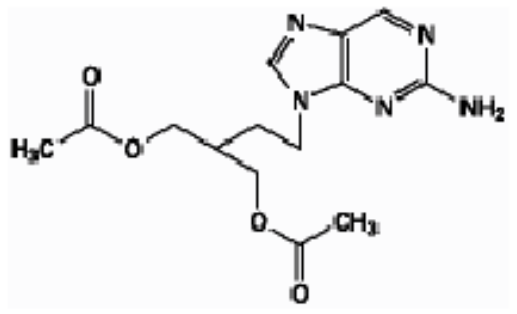

Figure 1. Structure of famciclovir

\section{Experimental}

\section{Apparatus}

Two different HPLC systems were used for the study. The corresponding specifications are given below.

HPLC system 1: the HPLC 1 apparatus was a Waters chromatographic system equipped with an injection valve (Rheodyne 033381); Waters 2487 UV dual $\lambda$ absorbance detector was used. A reversed-phase C18 column $(25 \mathrm{~cm} \times 4.6 \mathrm{~mm}$ i.d., particle size $5 \mu \mathrm{m})$. Peak area integration was performed using Breeze software. HPLC system 2: The HPLC 2 apparatus was a Shimadzu chromatographic system with two LC- 10AT VP pumps, variable wavelength programmable UV/Visible detector SPD-10A, VP CTO, - 10 AS VP column oven (Shimadzu) A reversed-phase $\mathrm{C} 18$ column $(150 \mathrm{~cm} \times 4.6 \mathrm{~mm}$ i.d., particle size $5 \mu \mathrm{m}$; 
YMC, IMC, Wilmington, NC, 28403, U.S.A.) and the HPLC system was monitored by software "Class-VP series version 5.03 (Shimadzu)". A model SL-164 UV-Visible spectrophotometer (Elico Ltd, India) was employed for spectrophotometric study. The experimental design and statistical analysis of the data were performed, by statistica ${ }^{15}$ data analysis software system, with using central composite design (CCD) and 16 runs for robustness study.

\section{Reagents and chemicals}

HPLC grade Methanol, potassium dihydrogenphosphate (A.R grade) and orthophosphoric acid (A.R.grade) was obtained from Quiligens (Mumbai, India). Pure sample of drug and internal standard were obtained from Cipla laboratories Ltd. Mumbai India and Sun Pharmaceutical Ltd Baroda India respectively. Triple distilled water obtained using a Milli-Q® UF-Plus apparatus (Millipore) was used to prepare all solutions for the method. The determination of FCV in commercial formulation was carried out (famtrex, varovir $250 \mathrm{mg}$ ). Phosphate buffer was prepared and $\mathrm{p}^{\mathrm{H}}$ was adjusted to require with orthophosphoric acid.

\section{Preparation of the standard solution}

An accurately weighed sample $(100 \mathrm{mg})$ of FCV reference standard was transferred to a $100 \mathrm{~mL}$ volumetric flask and dissolved in triple distilled water to make a solution $(1 \mathrm{mg} / \mathrm{mL})$. From this solution, a working standard solution of $100 \mu \mathrm{g} / \mathrm{mL}$ of strength was prepared from this dilution of $5,10,20,30$, and $40 \mu \mathrm{g} / \mathrm{mL}$ were made in $10 \mathrm{~mL}$ volumetric flasks with the mobile phase here in every standard solution contains $5 \mu \mathrm{g} / \mathrm{mL}$ of pramipexole internal standard. To carry out the assay aliquots of FCV solution equal to $5,10,20,30$ and $40 \mu \mathrm{g} / \mathrm{mL}$ were accurately withdrawn.

\section{Extraction of FCV from tablets}

About 20 tablets of famtrex, varovir (each tablet contains $250 \mathrm{mg}$ of famciclovir as API) were weighed and thoroughly powdered. The amount of powder equivalent to about $100 \mathrm{mg}$ was placed in a $100 \mathrm{~mL}$ volumetric flask. To it around $90 \mathrm{~mL}$ of solvent (water) was added and the flask was placed in an ultrasonic bath for $15 \mathrm{~min}$. The solution was then cooled and diluted to volume with the same solvent. The solution was filtered though a $0.45 \mu \mathrm{m}$ filter and then the filtrate were used to prepare sample solutions of different concentrations.

\section{Calibration procedure}

The calibration curve was plotted with five concentrations of the standard solution 5-40 $\mu \mathrm{g} / \mathrm{mL}$ solutions and chromatography was repeated thrice for each dilution. The linearity was evaluated by linear regression analysis, which was calculated by the least square regression method. Before injecting solutions, the column was equilibrated for at least 30 min. with the mobile phase flowing through the system. Quantitation was accomplished using an internal standard method. Five determinations were carried out for each solution. Peak area ratios were recorded for all the solutions. The correlation graph was constructed by plotting the peak area ratios obtained at the optimum wavelength of detection versus the injected amounts of the respective concentrations.

\section{Chromatographic conditions}

The mobile phase was a mixture of Methanol and phosphate buffer $(50: 50, v / v)$, flow rate was $1.0 \mathrm{~mL} / \mathrm{min}$. The UV detector wavelength was set at $242 \mathrm{~nm}$ and the temperature was set at $23 \pm 1{ }^{\circ} \mathrm{C}$. 


\section{Results and Discussion}

The applied chromatographic conditions permitted a good separation of FCV $5 \mu \mathrm{g} / \mathrm{mL}$ and the internal standard pramipexole $5 \mu \mathrm{g} / \mathrm{mL}$ (Figure 2), no drug decomposition was observed during the analysis. The LC method was validated for the parameters reported below.

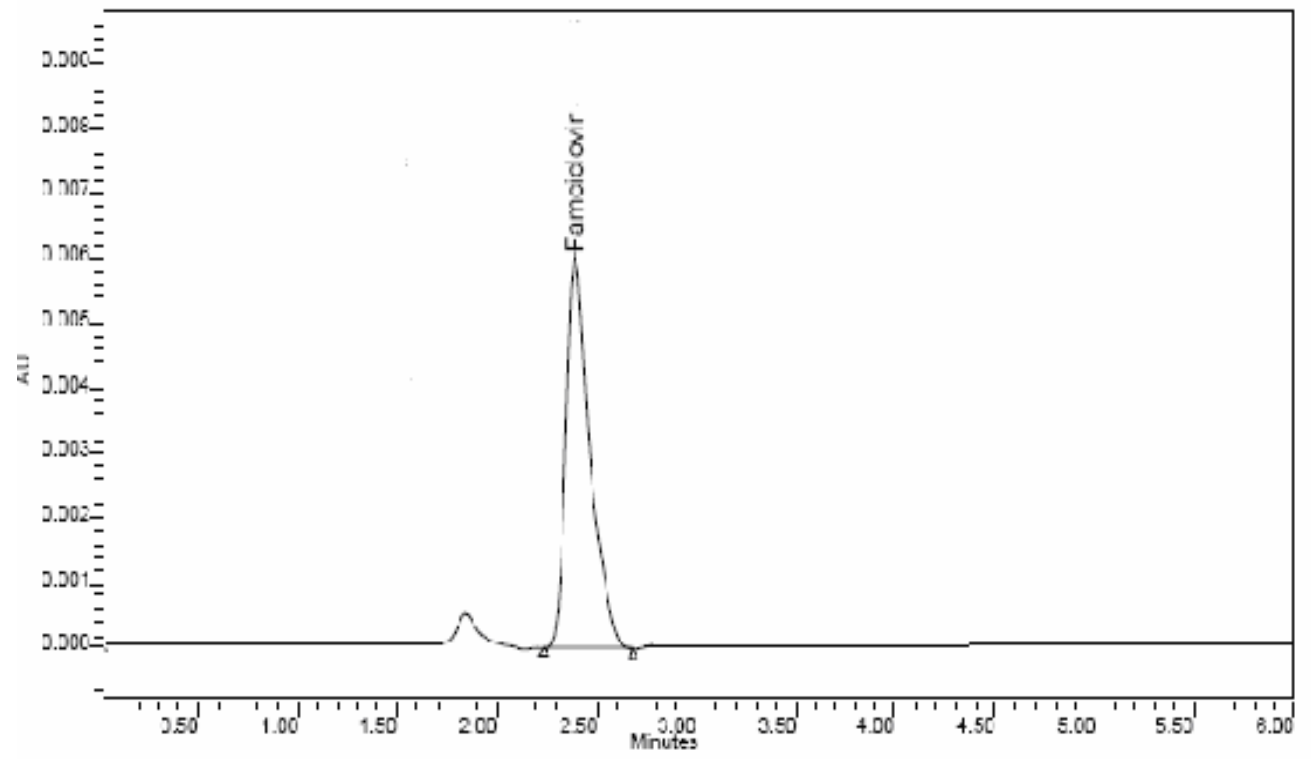

Figure 2. Chromatogram of famciclovir.

Stability of the solution

Results obtained in the study of the solution (both reference and sample solution) where It can be noticed that solutions were stable for $48 \mathrm{~h}$, as during this time the results does not decrease below the minimum percentage $(98 \%)$.

\section{Linearity}

FCV and internal standard were chromatographed using the mobile phase. The linearity of peak area responses versus concentrations was studied from 5- $40 \mu \mathrm{g} / \mathrm{mL}$ for FCV. A linear response was observed over the examined concentration range. The results are tabulated Table 1.

Table 1.Results of the data analysis for the quantitative determination of famciclovir by the proposed method.

\begin{tabular}{ll}
\hline Statical parameter & HPLC \\
\hline Concentration range, $\mathrm{g} / \mathrm{mL}$ & $5-40$ \\
Regression equation & $\mathrm{y}=0.2549 \mathrm{x}-0.06903$ \\
Correlation coefficient $(\mathrm{r})$ & 0.9999 \\
Stand error on estimation(Se) & -0.0326 \\
Standard deviation on $\operatorname{slope}(\mathrm{Sb})$ & 0.0008 \\
Standard deviation on intercept $(\mathrm{Sa})$ & 0.0231 \\
Limit of detection $(\mathrm{LOD}) \mu \mathrm{g} / \mathrm{mL}$ & 0.18 \\
Limit of quantification $(\mathrm{LOQ}) \mu \mathrm{g} / \mathrm{mL}$ & 0.6 \\
\hline
\end{tabular}




\section{Accuracy and repeatability}

Accuracy was studied using three different test solutions, containing 10, 20 and $30 \mu \mathrm{g} / \mathrm{mL}$ of FCV. Recovery data are reported in Table 2 . The obtained values were within the range of 97.45 and $101.60 \%$, mean RSD\% was $0.72 \%$, satisfying the acceptance criteria for the study. The system repeatability was calculated from five replicate injections of FCV at the analytical concentration of about $10 \mu \mathrm{g} / \mathrm{mL}$; the RSD\% found was 0.79 .

Table 2. Accuracy for famciclovir

\begin{tabular}{lll}
\hline Concentration, $\mu \mathrm{g} / \mathrm{mL}$ & Recovery, ${ }^{\mathrm{a}}$ & $\mathrm{RSD}, \%$ \\
\hline 10 & 97.45 & 0.38 \\
20 & 101.57 & 0.81 \\
30 & 98.03 & 0.98 \\
Mean & 99.01 & 0.72 \\
\hline \multicolumn{3}{c}{}
\end{tabular}

\section{Robustness}

As defined by the ICH, the robustness of an analytical procedure describes to its capability to remain unaffected by small and deliberate variations in method parameters ${ }^{12-13}$. In order to study the simultaneous variation of the factors on the considered responses, a multivariate approach using design of experiments is recommended in robustness testing. A response surface method was performed to obtain more information and to investigate the behavior of the response around the nominal values of the factors. Response surface methodology (RSM) has the following advantages: (a) to allow a complete study where all interaction effects are estimated; and (b) to give an approximate description of an experimental region around a center of interest with validity of interpolation ${ }^{14,16,17}$. Generally the large numbers of experiments required by standard designs applied in RSM disenchant their use in the validation procedure. However, if an analytical method is fast and requires the testing of a few factors (three or less), a good choice for robustness testing may be the central composite design (CCD), widely employed because of its high efficiency with respect to the number of runs required. A CCD in $k$ factors requires $2^{\mathrm{K}}$ factorial runs, $2 k$ axial experiments, symmetrically spaced at $\pm \alpha$ along each variable axis, and at least one center point. Two to five center repetitions are generally carried out in order to know the experimental error variance and to test the predictive validity of the model ${ }^{19}$. In order to study the variables at no more than three levels $(-1,0,+1)$, the design used in robustness testing of FCV was a central composite design (CCD) with $\alpha= \pm 1^{16,20}$. Three factors were considered: percentage $\mathrm{v} / \mathrm{v}$ of methanol $(x 1)$; flow rate $\mathrm{mL} \mathrm{min}^{-1}\left(x_{2}\right)$ and $\mathrm{pH}(x 3)$ at the concentration of $10 \mu \mathrm{g} / \mathrm{mL}$ of test solution. The experimental domain of the selected variables is reported in Table 3 . The ranges examined were small deviations from the method settings and the corresponding responses in the peak area ratio considered $(Y)$ were observed. A three-factor CCD requires 16 experiments, including two replicates of the center point. The experimental plan and the corresponding responses are reported in Table 4. All experiments were carried out in randomized order to minimize the effects of uncontrolled factors that may introduce a bias on the response. A classical second-degree model with a cubic experimental domain was postulated. Experimental results were computed by statistica ${ }^{15}$. The coefficients of the second-order polynomial model were estimated by the least squares regression. The equation model for $Y$ (found peak area ratio) was as follows:

$$
\begin{aligned}
& Y=1.109951-0.001829 x_{1}-0.014010 x_{2}+0.007012 x_{3}-0.00317 x_{1}{ }^{2}-0.022620 x_{2}{ }^{2}- \\
& 0.021942 x_{3}{ }^{2}+0.01 x_{1} x_{2}+0.00 x_{1} x_{3}-0.0025 x_{2} x_{3}
\end{aligned}
$$

The factors flow rate $(x 2)$ and methanol $(\mathrm{x} 1)$ and $\mathrm{pH}(\mathrm{x} 3)$ were significant for the regression model assumed in decreasing order. 
Table 3. Chromatographic conditions and range investigated during robustness testing.

\begin{tabular}{lcc}
\hline Variable & Optimized value & Range investigated \\
\hline Mobile phase (Methanol / buffer ) & $50: 50$ & 42.58 \\
Flow rate, mL / min & 1.0 & $0.6-1.2$ \\
$\mathrm{pH}$ & 3.0 & $2.2-3.8$ \\
\hline
\end{tabular}

Table 4. Experimental plan for robustness and obtained response.

\begin{tabular}{ccccr}
\hline Exp. No. & Methanol, \% & Flow rate, $\mathrm{mL} \mathrm{min}^{-1}$ & $\mathrm{pH}$ & Peak area ratio \\
\hline 1 & 45 & 1.2 & 2.5 & 1.02 \\
2 & 58 & 1.0 & 3.0 & 1.02 \\
3 & 50 & 1.0 & 3.0 & 1.11 \\
4 & 50 & 1.0 & 2.2 & 1.03 \\
5 & 55 & 1.2 & 3.5 & 1.04 \\
6 & 42 & 1.0 & 3.0 & 1.01 \\
7 & 50 & 1.3 & 3.0 & 1.02 \\
8 & 55 & 0.8 & 2.5 & 1.03 \\
9 & 45 & 1.2 & 3.5 & 1.03 \\
10 & 50 & 0.6 & 3.0 & 1.04 \\
11 & 55 & 1.2 & 2.5 & 1.05 \\
12 & 50 & 1.0 & 3.0 & 1.12 \\
13 & 45 & 0.8 & 2.5 & 1.05 \\
14 & 55 & 0.8 & 3.5 & 1.05 \\
15 & 45 & 0.8 & 3.5 & 1.03 \\
16 & 50 & 1.0 & 3.8 & 1.05 \\
\hline
\end{tabular}

The model was validated by the analysis of variance (ANOVA). The statistical analysis showed (Table 5) that the model represents the phenomenon quite well and the variation of the response was correctly related to the variation of the factors, Figure 3 shows the influence of each of the variables studied in the FCV as a response where flow rate, percentage of organic modifier and $\mathrm{pH}$ have considerable effect as decreasing order. The interpretation of the results has to start from the analysis of the whole model equation rather than from the analysis of the single coefficients. It is important for the response surface study, to consider also the factors whose coefficients are statistically nonsignificant. For this reason the analysis of the response surface plot is necessary. As shown in Fig. 4(a-c), the analysis produces three-dimensional graphs by plotting the response model against two of the factors, while the third is held constant at a specified level, usually the proposed optimum. Fig. 4a shows a graphical representation of the isoresponse surface for variation of percentage of methanol ( $x 1)$ and flow rate $(x 2)$, while the $\mathrm{p}^{\mathrm{H}}\left(x_{3}\right)$ is maintained constant at its optimum of 3.0. An increase in the flow rate results in a decrease of the observed peak area ratio $(Y)$, while the $\mathrm{pH}$ had no important effect on the response. Analogous interpretation may be derived by examining Fig. $4 \mathrm{c}$ that plots the factors flow rate $(x 2)$ versus $\mathrm{pH}(x 3)$. In Fig. $4 \mathrm{~b}$, where the factor flow rate is maintained constant, the method can be considered robust for the studied experimental response. In conclusion, by examining the ANOVA results and analysis of response surface confirms that $Y$ is not robust for factor $x 2 \& \mathrm{x} 1$, moderately to $\mathrm{x} 3$ thus a precautionary statement should be included in the analytical procedure for this result. 


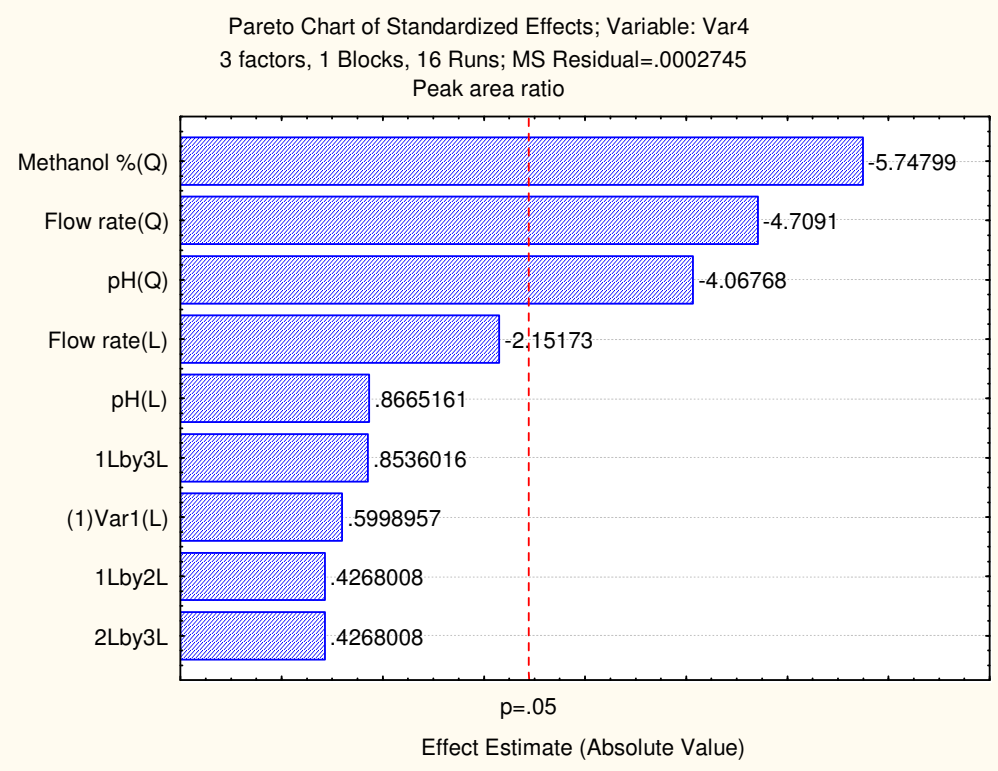

Figure 3. Pareto chart of standard effects : \% Methol, Flow rate, $\mathrm{pH}$ and combination of these in decreasing order of significance for this method

Table 5. ANOVA results

\begin{tabular}{cccc}
\hline Parameter & SS & F & p \\
\hline Methanol, \% & 0.009 & 33.03 & 0.001 \\
Flow rate, $\mathrm{mL} / \mathrm{min}^{-1}$ & 0.006 & 22.17 & 0.002 \\
$\mathrm{P}^{\mathrm{H}}$ & 0.004 & 16.54 & 0.006 \\
\hline
\end{tabular}

Table 6. Experimental plan for Intermediate precision testing and obtained responses

\begin{tabular}{ccllc}
\hline Exp. No. & Analyst & Instrument & Day & Peak area ratio \\
\hline 1 & 1 & HPLC 1 & 1 & 1.03 \\
2 & 1 & HPLC 1 & 1 & 1.04 \\
3 & 1 & HPLC 1 & 1 & 1.06 \\
4 & 2 & HPLC 1 & 1 & 1.08 \\
5 & 2 & HPLC 1 & 1 & 1.07 \\
6 & 2 & HPLC 1 & 1 & 1.08 \\
7 & 1 & HPLC 2 & 1 & 1.12 \\
8 & 1 & HPLC 2 & 1 & 1.10 \\
9 & 1 & HPLC 2 & 1 & 1.13 \\
10 & 2 & HPLC 2 & 1 & 1.10 \\
11 & 2 & HPLC 2 & 1 & 1.03 \\
12 & 2 & HPLC 2 & 2 & 1.11 \\
13 & 1 & HPLC 1 & 2 & 1.03 \\
14 & 1 & HPLC 1 & 2 & 1.03 \\
15 & 1 & HPLC 1 & 2 & 1.03 \\
16 & 2 & HPLC 1 & 2 & 1.04 \\
17 & 2 & HPLC 1 & 2 & 1.05 \\
18 & 2 & HPLC 1 & 2 & 1.08 \\
19 & 1 & HPLC 2 & 2 & 1.10 \\
20 & 1 & HPLC 2 & 2 & 1.09 \\
21 & 1 & HPLC 2 & 2 & 1.05 \\
22 & 2 & HPLC 2 & 2 & 1.12 \\
23 & 2 & HPLC 2 & 2 & 1.07 \\
24 & 2 & HPLC 2 & 2 & 1.06 \\
\hline
\end{tabular}


Desirability Surface/Contours; Method: Spline Fit
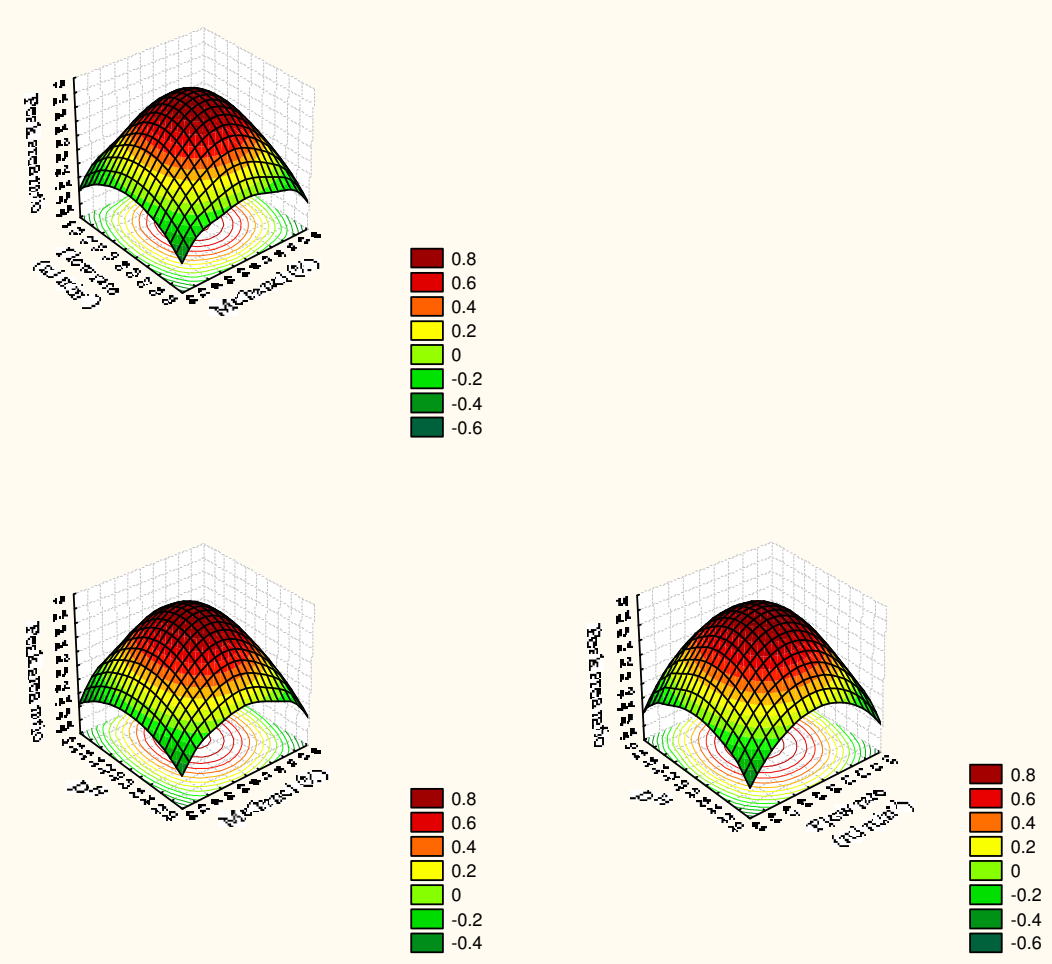

Figure 4. Three-dimensional plot of the response surface for $Y$ (found drug peak area ratio). (a) Variation of the response $\mathrm{Y}$ as a function of $\mathrm{x}_{1}\left(\%\right.$ methanol) and $\mathrm{x}_{2}$ (flow rate);fixed factor: $\mathrm{x}_{3}(\mathrm{pH})=3.0$ (b) Variation of the response $\mathrm{Y}$ as a function of $\mathrm{x}_{1}(\%$ methanol) and $\mathrm{x}_{3}(\mathrm{pH})$ fixed factor: $\mathrm{x}_{2}$ (flow rate ) $=1.0 \mathrm{~mL} \min ^{-1}$ (c) Variation of the response $\mathrm{Y}$ as a function of $\mathrm{x}_{2}$ (flow rate) and $\mathrm{x}_{3}(\mathrm{pH})$; fixed factor $\mathrm{x}_{1}(\%$ methanol $)=50 \% \mathrm{v} / \mathrm{v}$

\section{Intermediate Precision}

The intermediate precision is a measure of precision between repeatability and reproducibility and it should be established according to the circumstances under which the procedure is intended to be used ${ }^{21}$. The analyst should establish the effects of random events on the precision of the analytical procedure. The intermediate precision is obtained when the assay is performed by multiple analysts, using multiple instruments, on multiple days, in one laboratory ${ }^{12}$. In order to study these effects simultaneously, a multivariate approach was used. The considered variables included analysts ( 1 and 2), equipment (HPLC 1 and 2) and days ( 1 and 2). The considered response was the found drug peak area ratio. A linear model $(y=b 0+b 1 x 1+b 2 \times 2+b 3 \times 3)$ was postulated and a 23 full factorial design was employed to estimate the model coefficients. Each experiment was repeated three times in order to evaluate the experimental error variance. The analyses were carried out in a randomized order according to the experimental plan reported in Table 6. The concentration of famciclovir was about $10 \mu \mathrm{g} / \mathrm{mL}$ of test solution No considered factor was found significant for the regression model assumed. The RSD found $(0.86 \%, n=24)$ was acceptable, indicating 
a good precision of the analytical procedure. The proposed method was compared to the UV spectrophotometry (fig.5) to verify the results obtained from HPLC. A calibration equation was obtained in the concentration range of $10-50 \mu \mathrm{g} \mathrm{mL}^{-1}$ and at the wavelength of $305 \mathrm{~nm}$ by using water as a blank. The relation between absorbance $(A)$ and concentration of famciclovir $(C)$ was $[A=1763 C-0.0352 ; r=0.9982]$. The tablet analysis results were found to be $9.8 \pm 0.4($ mean $\pm \mathrm{SD} ; n=6)$ by $\mathrm{UV}$ spectrophotometry ${ }^{22}$ ]. High reproducibility and insignificant differences between the two methods were obtained at the $95 \%$ probability level for $t$ - and $F$-test of significance of $1.63<2.46$ and $2.56<4.12$, respectively.

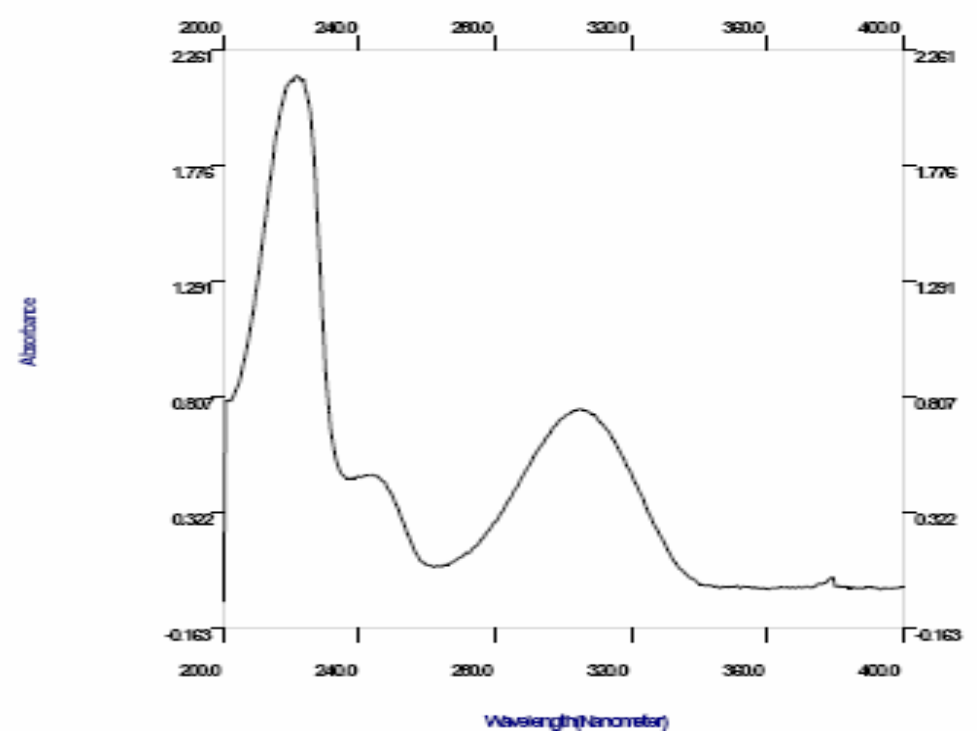

Figure 5. Famciclovir UV Spectrum at $10 \mu \mathrm{g} / \mathrm{mL}$

\section{Conclusions}

The proposed high-performance liquid chromatographic method has been evaluated over the linearity, precision, accuracy, specificity and proved to be convenient and effective for the quality control of famciclovir in given application. The measured signal was shown to be precise, accurate, and linear over the concentration range tested $(5.0-40.0 \mu \mathrm{g} / \mathrm{mL})$ with a correlation coefficient better than 0.9999 . The proposed method was further compared with an UV method reported by us and proved to be acceptable accuracy and precision. Moreover, the lower solvent consumption leads to a cost effective and environmentally friendly chromatographic procedure. Thus, the proposed methodology is rapid, selective, requires a simple sample preparation procedure, and represents a good procedure of famciclovir determination in pharmaceutical dosage forms.

\section{Acknowledgment}

The authors thank to M/s Cipla laboratories Mumbai India and Sun pharmaceuticals Ltd. Baroda India for providing pure drugs to develop the method, Dr. K.Rama Krishna UGC research awardee department of chemistry Andhra University and G.G. Sankar associate professor from Shri Vishnu College of Pharmacy for their help during the work. 


\section{References}

1. Candaele M, Candaele D, Seventh International Conference on Antiviral Research (Abstract 118), Charlesston, South Carolina, 27 February -4 March 1994.

2. Stephen Tyring, Br. J. Ophthalmol. 2001, 85, 576-581

3. Perry C M, and Wagstaff A J, Drugs, 1995, 50, 396-415.

4. Vere Hodge R A and Cheng Y C, Antiviral Chem.Chemother. 1993, 4(Suppl. 1), 13-24.

5. Arabian F A and Sacks S L, Drugs, 1996, 52, 17-32.

6. Pue M A and Benet L Z, Antiviral Chem.Chemother. 1993, 4(Suppl. 1), 47-55

7. Murray A B, Antiviral Chem. Chemother. 1995. 6, 34-38,

8. Vere Hodge R A, Sutton D, Boyd M R, Harnden M R and Jarvest R L, Antimicrob. Agents Chemother. 1989, 33, 1765-1773.

9. Schenkel F, Rudaz S, Daali Y, Kondo Oestreicher M. Veuthey L and Dayer P, J.Chromatogr. 2005, B 826, 1-7.

10. Briony Brand, Colin B. Reese, Tetrahedron, 1999, 55 (5), 5239-5252.

11. Zhang Y S, Wang L Q, Guo Y J, Cui J G Li, J Zhongguo Yiyao Gongye Zazhi, 2002, 33 (9) , 454-457

12. Topic Q2B, Validation of Analytical Methods: Methodology. The Third International Conference on Harmonization of Technical Requirements for Registration of Pharmaceuticals for Human Use, International Conference on Harmonisation, (ICH) Yokohama, Japan, 1997.

13. Vander Heyden Y, Nijhuis A, Smeyers-Verbeke J, Vandeginste B G M, J. Pharm. Biomed. Anal. 2001, 24, 723-753.

14. Lin D K, J. Quality Technol. 1999, 31, 61-66.

15. Stat soft, Inc, Statistica data analysis system, Statistica software east $230014^{\text {th }}$ street, Tulsa, 2001, Ok 74104.

16. Hockman K K and Berengut D, Chem. Eng. 1995, 102, 142-148.

17. Fabre H, J. Pharm. Biomed. Anal. 1996, 14, 1125-1132.

18. Ragonese R, Mulholland M and Kalman J, J. Chromatogr. A 2000, 870, 45-51

19. Lewis G A, Mathieu D and Phan-Tan-Luu R, Pharmaceutical Experimental Design, Marcel Dekker, New York, 1999.

20. Pinzauti S, Gratteri P, Furlanetto S, Mura P, Dreassi E and Phan-Tan-Luu R, J. Pharm. Biomed. Anal. 1996, 14, 881-889.

21. Joachim Ermer and Hans-Joachim Ploss, J. Pharm. Biomed. Anal, 2005, 37, 859.

22. Srinu babu G, Babu IS, Kumar NK, Yugandhar NM, Raju Ch AI, Asian J. Chem. 2007, 19, 1636. 


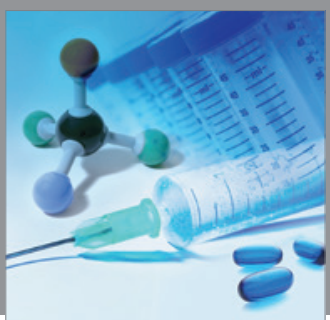

International Journal of

Medicinal Chemistry

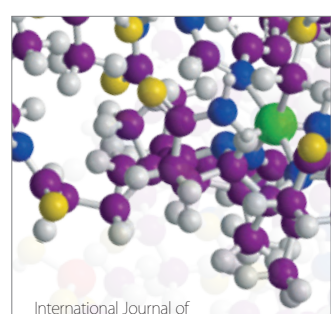

Carbohydrate Chemistry

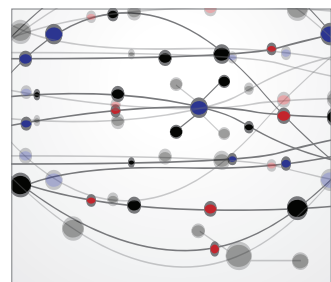

The Scientific World Journal
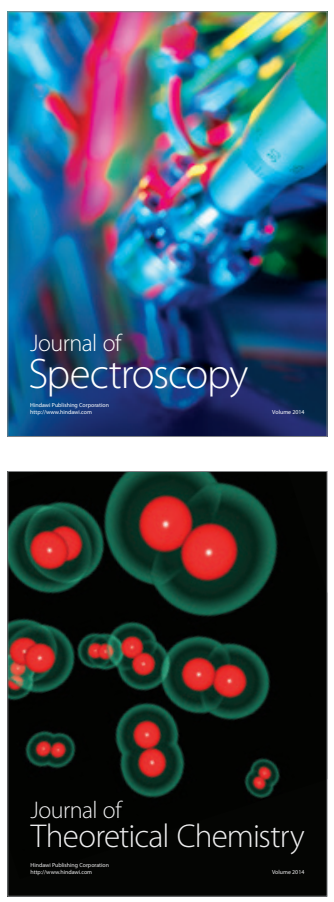
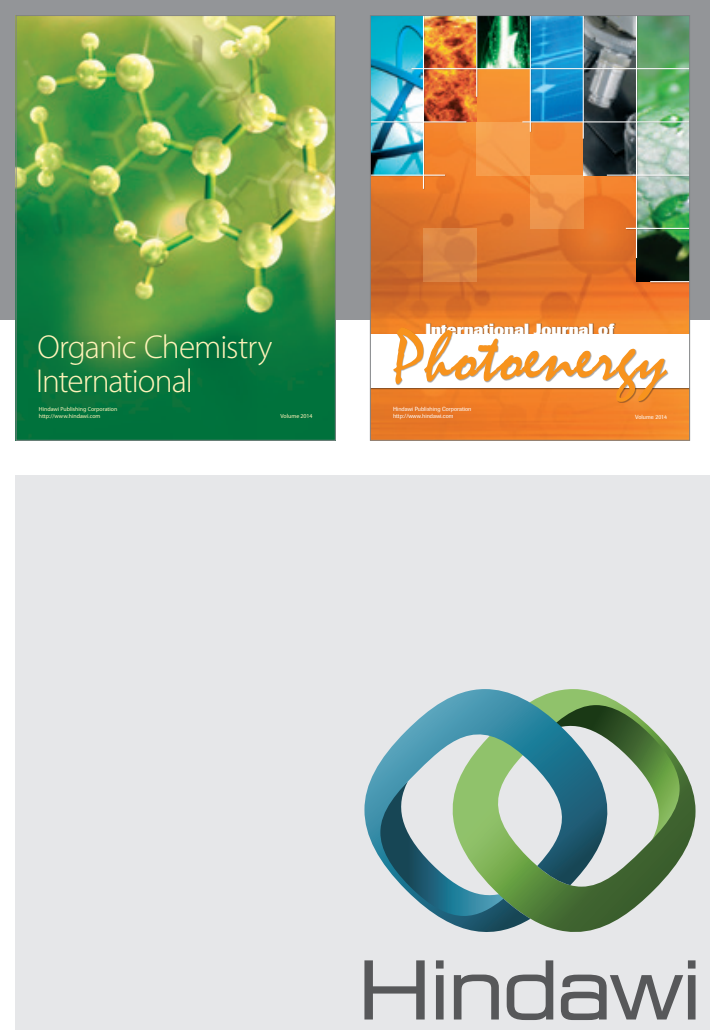

Submit your manuscripts at

http://www.hindawi.com
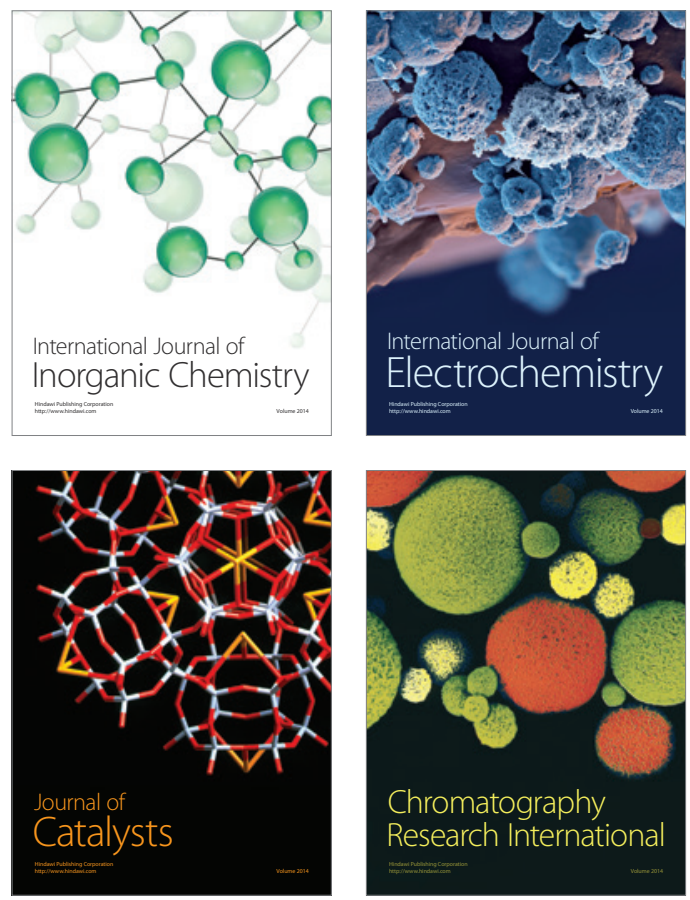
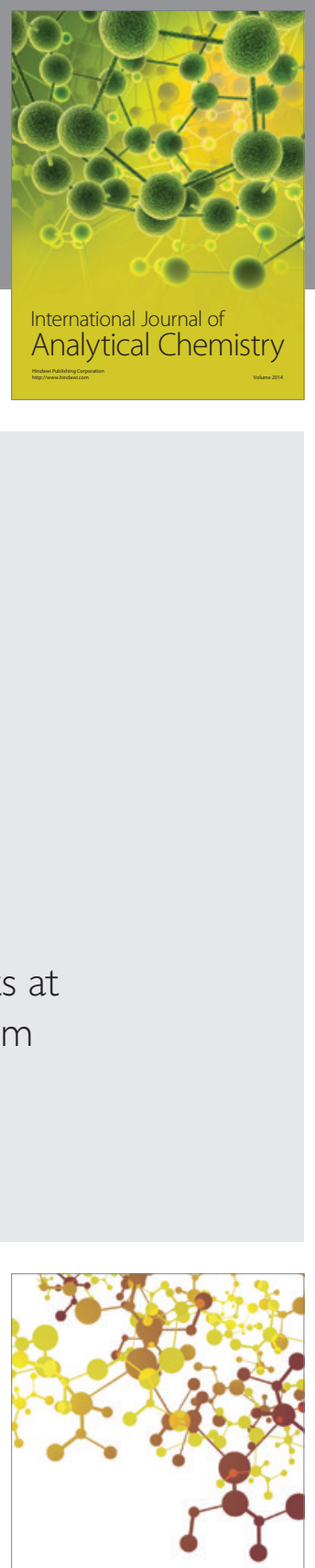

Journal of

Applied Chemistry
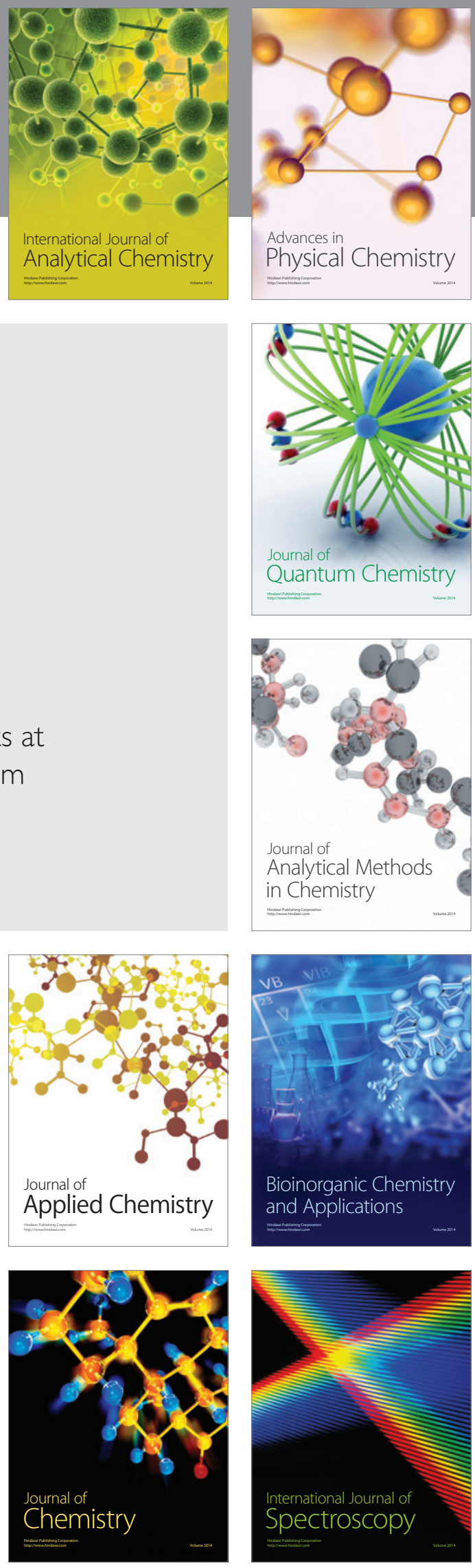